\title{
Chronic Smoking and Buerger's Disease: A Hospital Based Study
}

\author{
Shamim Akhtar ${ }^{1}$, Gumashta Jyotsna ${ }^{2}$, Gumashta Raghvendra ${ }^{3 *}$ \\ ${ }^{1}$ Department of Pathology, N.K.P. Salve Institute of Medical Sciences and Research Centre, Nagpur, \\ Maharashtra, India \\ ${ }^{2}$ Department of Physiology, People's College of Medical Sciences \& Research Centre, Bhopal, Madhya \\ Pradesh, India \\ ${ }^{3}$ Department of Community Medicine, N.K.P. Salve Institute of Medical Sciences and Research Centre, Nagpur, \\ Maharashtra, India
}

\begin{abstract}
Introduction: The role of tobacco smoking and Buerger's Disease has been examined in different countries. However, still there is need to understand the basic pathology and the conclusive important reasons of its causation because of differing observations among smokers of various socio-economic and geopolitical settings. Hence, the study highlights the scenario, as observed in a developing country, for further designing and undertaking of the research in this regards.

Purpose: To assess the prevalence of Buerger's Disease among various groups of traditionally used locally manufactured bidi smokers.

Materials and methods: The use of pre-designed questionnaire in this hospital based study was followed by venography and arteriography in the affected patients.

Results: Smoking was found highly associated with Bidi Smoking in terms of duration and frequency of smoking. The location of lesions and their commonality was also ascertained.

Conclusion: Cessation of using unfiltered locally made Bidi smoking is required for minimizing the cases of Buerger's Disease.
\end{abstract}

Key words: Angiography; Buerger's Disease; Thromboangitis obliterans; Venography.

\section{Introduction}

"Buerger's disease" is also known as Thromboangitis obliterans and now generally accepted as a definite pathologic entity. The cause of Buerger's disease is unknown. However, use of tobacco is central in the initiation and progression of disease. [1] The case for considering tobacco smoking as a more direct aetiological factor is mainly on clinical grounds which highlights the fact that there is extremely low incidence of nonsmokers and the high incidence of high smokers among the patients who have the disease, improvement of signs and symptoms consequent upon stoppage of tobacco, rarity of development of new lesion of superficial phlebitis and further arterial occlusion in patients who have the disease after stopping smoking.

In addition, tobacco smoking is primary aetiologic factor in thromboangitis obliterans because (a) there are many heavy smokers in this world, but the incidence of disease is very small and females are not affected; (b) in heavy smokers the disease does not appear until they have used tobacco for a period of 5-15 years; (c) rarely the new lesions appear in arteries or veins even after cessation of smoking; (d) the disease is seen in relatively mild smokers, and it has been reported in a few cases in non-smokers.

In view of the above, if tobacco smoking is considered the primary aetiologic factor, it may be theorized (a) that a relatively small number of persons have blood vessels which are susceptible to injury by some of the products of tobacco smoke; (b) that this susceptibility of idiosyncrasy is manifested by slow changes in isolated segments which develop over a period of months or years and finally reach the point where they become severe enough to produce thrombosis or occlusion; (c) that until occlusion takes place, the disease is not manifest clinically; (d) that idiosyncrasy usually, but not always, persists throughout life, and (e) that the disease process usually but not always, stops with the cessation of the use of tobacco.

\section{Methods}

The cases admitted to the surgical wards of a Medical College and Hospital during 10 months were taken into this study conducted in 1986-87. Twenty-four patients were selected. The criteria of selection included dry gangrenous changes; delayed healing with delayed line of demarcation and atrophic changes without loss of sensation; post-gangrenous ulcer with long history; approximate clinical evidence of ischaemia (i.e. pain, burning sensation, intermittent claudication, rest pain), onset before the age of 50 years, absent peripheral pulses, absence of atherosclerotic risk factors other than smoking, history of smoking and tobacco 
chewing for long duration i.e. 10-20 bidis per day since more than 5 years, history of ulceration and gangrenous changes in foot or digit; positive Buerger's test. [2]

In all twenty four cases, a routine and relevant history was taken and detailed physical and local examination of affected part was done.

Venography, defined as radiographic visualization of venous system was done by ascending phlebography. In this procedure, the scalp vein set was secured in a vein on the dorsum of foot and the dye was injected which as followed by X-ray of limb. After that 3 tourniquets were tied a) just above the ankle; b) one below the ankle joint; and, c) one above the knee joint. Again the dye was injected and picture taken.

The criteria of phlebographic venous thrombosis adn thrombophlebities included (a) In constant filling defect thrombi appear constant, sharply delineated filling defect surrounded by contrast, thrombi may be central and or eccentric and may be linear or hump shaped; (b) Abrupt termination of the opaque column occurs at a constant site in a vein either below or above the obstruction; (c) Non-filling of the entire deep system or portion thereof.

Femoral angiography (percutaneoous transfemoral angiography) was done in all patients to know the various changes in lower limb of thromboangitis obliterans. The technique of procedure included sensitivity testing of the dye by giving $1 \mathrm{ml}$ of contrast media intravenously by 1 in 10 dilution, thereafter the site of puncture was cleaned with spirit and betadine and 2\% xylocaine was injected locally. A 18 gauge intracath needle was introduced through the skin into the artery, the guide wire was passed through the intracath upto the common iliac artery. Intrapath was removed and the canula was introduced over the guide wire. Dye was injected and pictures were taken to know the flow of dye in various vessels of lower limbs.

Interpretation of angiogram was done. The site of obstruction is usually below femoropopliteal junction in patients of thromboangitis obliterans, but few cases with involvement of femoral artery are also seen. Usually sudden occlusion is seen, which is complete and there is no distortion of endothelium in thromboangitis obliterans. The involvement of the vessel is focal and segmental. Extent of collateral circulation is also looked for. Distal run off was defined as visualization of main vessel distal to the block. This visualization is because of dye entering the main vessels through collaterals.

\section{Results}

All the patients were between the age group of 20 to 55 years. The youngest was 20 years old, while the oldest was 52 years. The highest incidence of the disease was between the age 20 and 40 years (50\%). All the cases of thromboangitis obliterans, which were studied in this study, were males.

All the 24 patients in this study were smokers. 4 patients (17\%) smoked bidi for 1-10 years before the onset of the symptoms, 13 cases (54\%) were in the smoking duration range of 11-20 years duration and 5 cases (21\%) smoked in the range of $21-30$ years. The remaining 2 cases $(8 \%)$ were in the smoking duration range of more than 30 years before the onset of the symptoms. Out of 24 smokers, 8 cases $(33.33 \%)$ were mild smokers, 3 cases $(12.05 \%)$ were moderate smokers and the remaining 13 cases $(54.16 \%)$ were heavy smokers.

In 24 cases of Buerger's disease, 18 cases from this study (75\%) presented with complaints suggestive of intermittent claudication as the first presenting symptom. Burning pain and sensation in affected part and toes was seen in one patient (4\%). The highest number of cases $22(92 \%)$ were presented with ulceration and gangrene of variable periods and affecting the extremities.

Out of 13 angiographies, 9 were positive (69.23\%). Angiography showed findings of block in 1 case $(33.33 \%)$ out of 3 mild smokers. Four cases (66.66\%) out of 6 moderate smokers and remaining cases showed block in every case (100\%), who were heavy smokers. In case of mild smokers, 3 angiographies (23\%) were done, out of which $66.66 . \%$ were normal and $33.33 \%$ showed block below popliteal; while in case of moderate smokers $46.15 \%$ (6 angiographies) angiography showed complete block in $16.66 \%, 50 \%$ below femoral block and $33.33 \%$ normal. Heavy smokers showed $75 \%$ block below popliteal and $25 \%$ below femoral. Normal angiographies were $30.07 \%$.

Out of 10 patients for positive venography, evidence of thrombophlebitis was found in 1 case $(11.11 \%)$ out of 9 mild smokers; 3 cases $(42.86 \%)$ out of 7 moderate smokers and 6 cases $(66.66 \%)$ out of 9 cases of heavy smokers. In case of mild smokers, $36 \%$ venography was performed, out of which $11.11 \%$ had shown thrombus formation and $88.88 \%$ were normal.

Moderate smokers had shown $14.28 \%$ narrowing, $28.57 \%$ thrombus formation and $57.14 \%$ normal, out of $28 \%$ venographies. Remaining $36 \%$ of venographies had shown $11.11 \%$ thrombus formation, $11.11 \%$ narrowing and $44.44 \%$ showed complete block in case of heavy smokers.

\section{Discussion}

In a study by Olin JW et al, between 1970 and 1987, 112 patients were diagnosed as having thromboangiitis obliterans (TAO). The age was 42 +/- 11 years (mean +/- SD; range, 20-75 years); Ischemic ulcerations were present in 85 (76\%) patients: 24 (28\%) patients with upper-extremity, 39 (46\%) patients with lower-extremity, and $22(26 \%)$ patients with both upper- and lower-extremity lesions. Ninety-one (81\%) 
patients had rest pain, 49 (44\%) patients had Raynaud's phenomenon, and 43 (38\%) patients had superficial thrombophlebitis. Forty-three (48\%) patients stopped smoking for a mean of $80+/-105$ months (median, 46.5 months; range, 1-420 months), and only two (5\%) patients had amputations after they stopped smoking, while $22(42 \%)$ patients had amputations while continuing to smoke (p less than 0.0001) [3].

If tobacco plays part in affection of vein, it shows that tobacco products cause damage to the vein quite early and this damage increases steadily with increasing severity of smoking as evidenced by the findings of this study.

An analysis of the management and extended follow-up of the patients in a study has indicated that Buerger's disease, although rare, is a real clinical entity which can be diagnosed objectively. The relatively high rate of limb loss (31 percent of patients) documents the virulence of Buerger's disease involving the lower extremities. No major upper extremity amputations were required, and no patient lost further tissue after cessation of smoking. [4]

In another study it was observed that the poorer people tended to smoke 'biri', a locally made filterless cigarette with low-grade tobacco. It is interesting to speculate that this difference in the way tobacco is used might also partly explain the differences in incidence of Buerger's disease between Bangladesh and the West. [5]

In this study, mild smokers showed only $11.11 \%$ involvement. The percentage increases in moderate smokers. But, in heavy smokers, it is definitely increased and all the heavy smokers showed venographic abnormalities.

Whereas a study observed that good initial result gradually gave way to recurrence unless the patients discontinued smoking. The most important factor which decides natural history of Buerger's disease is smoking. [6]

Highlighting the causation of Buerger's disease one study emplhasized that the the role of second-hand smoke in the pathogenesis of Buerger's disease has not been seriously examined, although the authors have had anecdotal experience suggesting that this possible mechanism should be investigated. It is clear, however, that the use of tobacco is not the only factor in the disease's pathogenesis Buerger's disease is relatively uncommon, even in heavy smokers. Genetic factors likely play a role. Of note, the prevalence of Buerger's disease is greater in Eastern Europe and Asia than in the US. [7]

\section{Conclusion}

During the period of 10 months, 24 patients of Buerger's Disease were studied. The clinical diagnosis was based on history, socio-economic status and physical examination to establish the presence of chronic occlusive vascular disease, ischaemic changes in the skin, loss of pulse, ulcers and gangrene, intermittent claudication and thrombophlebitis between age group of 20-55 years.

It is concluded that all the patients were males below the age of 55 years, predominantly belonging to low socioeconomic group and having history of bidi (tobacco) smoking. In all the patients deep venous system was affected. Amongst the superficial venous system, long saphenous vein were maximally affected. Large veins like femoral and popliteal were not affected. As the duration of the diease increased, venous and arterial affections were more and only in late cases, venographic changes became more prominent. Severity of smoking had direct relationship with venous and arterial involvement. This could also suggest that the venous and arterial involvement is progressive with the continuation of smoking. Venography and Angiography studies give evidences of injury to the vessel wall with thrombosis, which suggest that in Buerger's disease primary pathology is vasculitis with secondary thrombosis.

\section{References:}

[1] Jeffrey W, Olin DO. Thromboangiitis Obliterans (Buerger's Disease). N Engl J Med Sep 2000; 343:864-869.

[2] Shigehiko Shionoya. Diagnostic criteria of Buerger's disease. International Journal of Cardiology 1998 Oct; 66(1) :S243-S245.

[3] Olin JW, Young JR, Graor RA, Ruschhaupt WF, Bartholomew JR. The changing clinical spectrum of thromboangiitis obliterans (Buerger's disease). Circulation. 1990 Nov;82(5 Suppl):IV3-8.

[4] Joseph L. Mills,Lloyd M. Taylor Jr, John M. Porter, Buerger's disease in the modern era. The American Journal of Surgery Jul 1987;154(1):123-139.

[5] W J Grove, Stansby F. Buerger's disease and cigarette smoking in Bangladesh. Annals of the Royal College of Surgeons of England 1992; 74:115-118.

[6] Shionoya S, Ban I, Nakata Y, Matsubara J, Hirai M, Kawai S. Surgical treatment of Buerger's disease. J Cardiovasc Surg (Torino). 1980 Jan-Feb;21(1):77-84.

[7] Szuba, Cooke. An Update on Buerger's Disease. WJM, Apr1998;168(4):256. 
Table I: Age and Sex incidence in Buerger's Disease

\begin{tabular}{|l|l|l|l|l|}
\hline S. No. & Age $($ in years $)$ & Sex & No. of Cases & Percentage $(\%)$ \\
\hline 1 & $21-30$ & Male & 6 & 25 \\
\hline 2 & $31-40$ & Male & 6 & 25 \\
\hline 3 & $41-50$ & Male & 10 & 4 \\
\hline 4 & 51 and above & Male & 2 & 8 \\
\hline Total & 24 & 100 \\
\hline
\end{tabular}

Table II: Duration of Smoking in Buerger's Disease.

\begin{tabular}{|l|l|l|l|}
\hline S. No. & $\begin{array}{l}\text { Duration } \\
\text { Smoking } \\
\text { in years) }\end{array}$ & No. of Cases & Percentage (\%) \\
\hline 1 & $1-10$ & 4 & 17 \\
\hline 2 & $11-20$ & 13 & 54 \\
\hline 3 & $21-30$ & 5 & 21 \\
\hline 4 & 31 and above & 2 & 8 \\
\hline Total & 24 & 100 \\
\hline
\end{tabular}

Table III: Frequency of smoking and Buerger's Disease.

\begin{tabular}{|l|l|l|l|l|}
\hline S. No. & Frequency & No. of Bidi/Day & No. of cases & Percentage $(\%)$ \\
\hline 1 & Mild & $11-20$ & 8 & 33.33 \\
\hline 2 & Moderate & $21-30$ & 3 & 12.51 \\
\hline 3 & Heavy & 31 and above & 13 & 54.16 \\
\hline Total & & 24 & 100 \\
\hline
\end{tabular}

Table IV: Symptomatology in Buerger's Disease.

\begin{tabular}{|l|l|l|l|}
\hline S. No. & Symptoms & No. of cases & Percentage (\%) \\
\hline 1 & Intermittent claudication & 18 & 75.0 \\
\hline 2 & Rest pain & 8 & 33.0 \\
\hline 3 & Burning sensation & 1 & 4.0 \\
\hline 4 & Ulcer and gangrene & 22 & 92.0 \\
\hline 5 & Superficial phlebitis & 1 & 4.0 \\
\hline 6 & Upper limb involvement & 1 & 4.0 \\
\hline
\end{tabular}

Table V: Relationship between frequency of smoking and angiographic block in Buerger's Disease.

\begin{tabular}{|l|l|l|}
\hline Frequency of Smoking & No. of patients with Angiography & No. of patients with positive block \\
\hline Mild & 3 & $1(33.33 \%)$ \\
\hline Moderate & 6 & $4(66.66 \%)$ \\
\hline Severe & 4 & $4(100 \%)$ \\
\hline
\end{tabular}

Table VI: Relationship between frequency of smoking and venographic evidences in ten cases of Buerger's Disease.

\begin{tabular}{|l|l|l|}
\hline Frequency of Smoking & No. of patients with Venography & No. of patients with positive block \\
\hline Mild & 9 & $1(11.11 \%)$ \\
\hline Moderate & 7 & $3(42.86 \%)$ \\
\hline Severe & 9 & $6(66.66 \%)$ \\
\hline
\end{tabular}




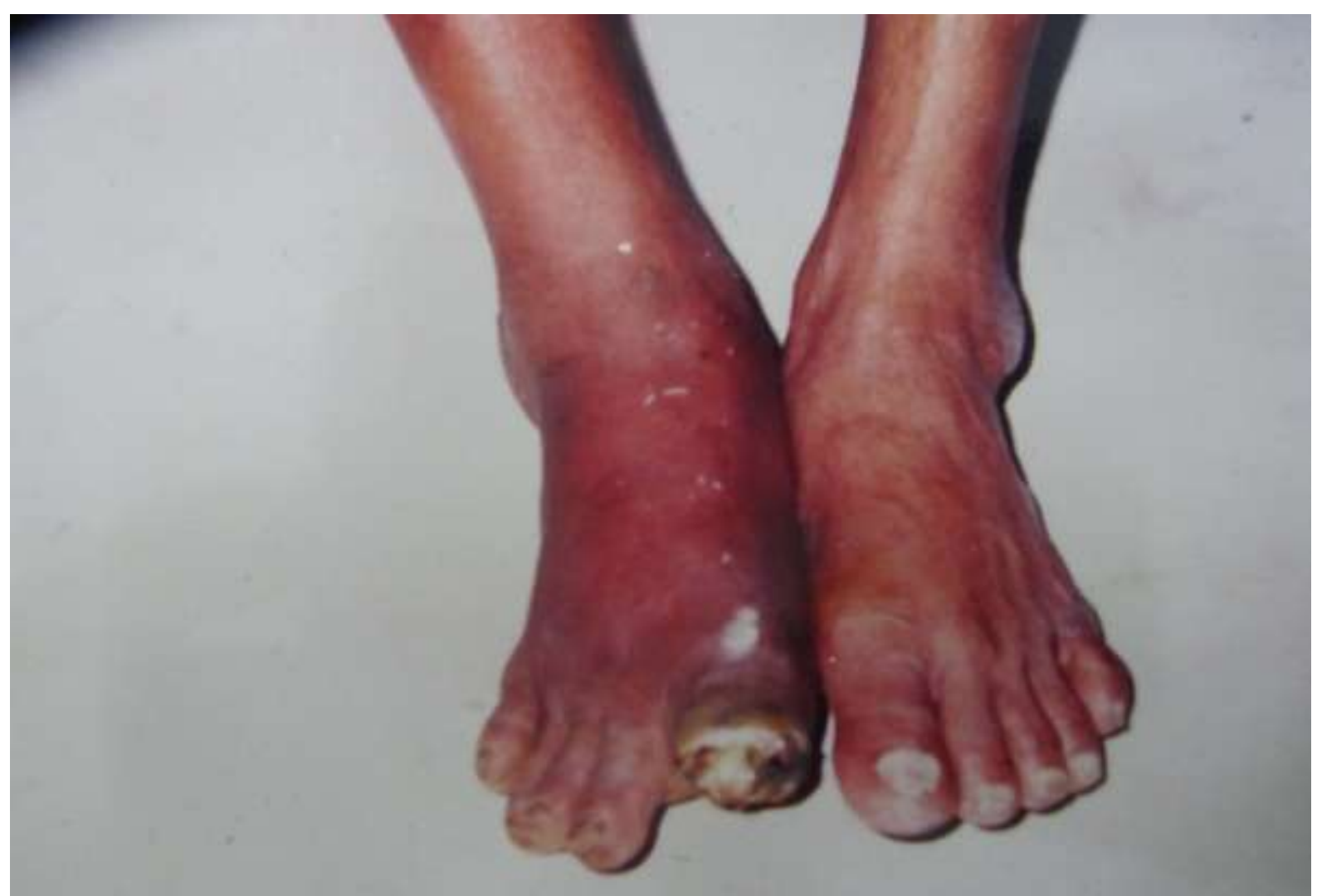

Fig 1. Showing clear line of separation.

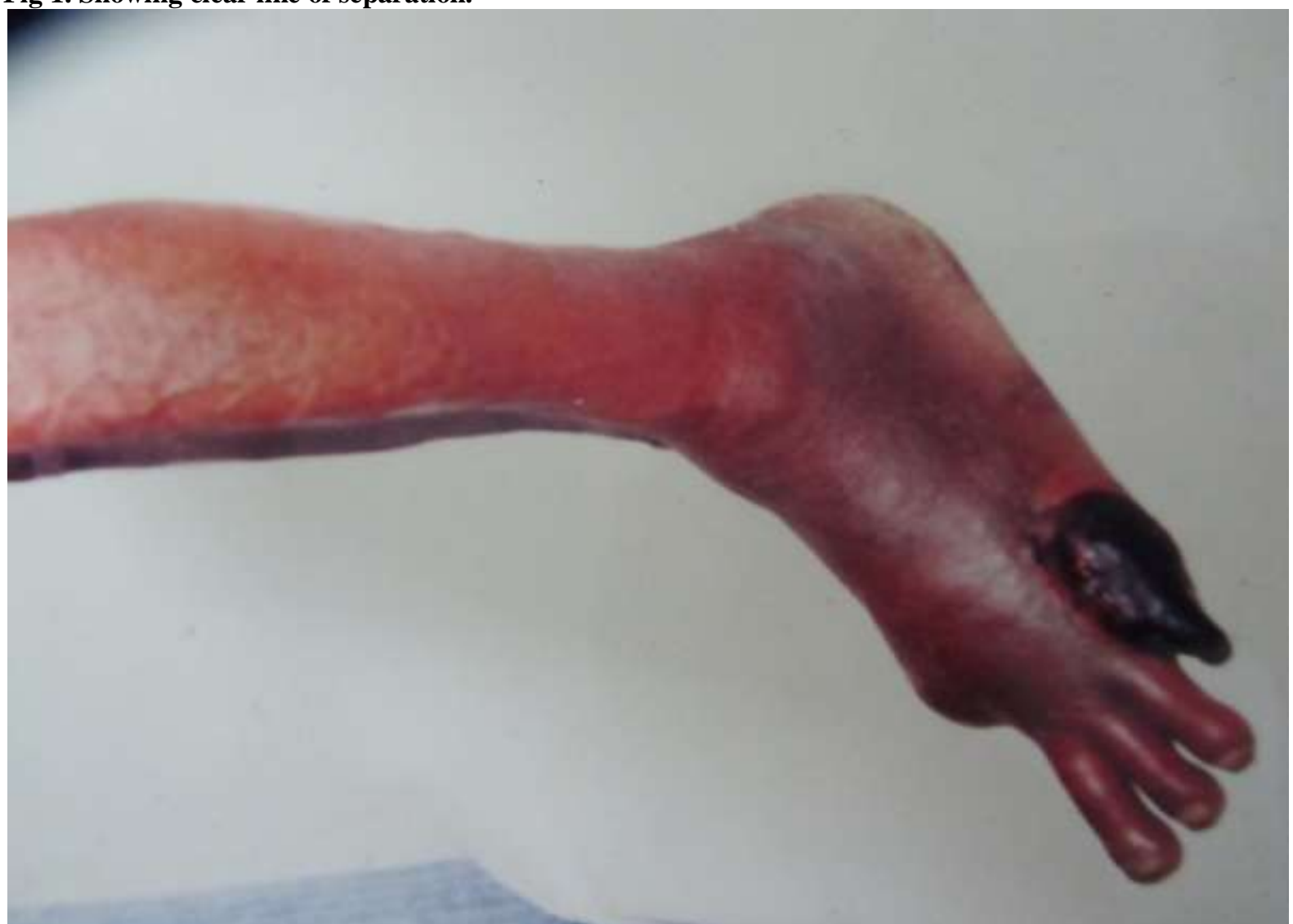

Fig 2. Showing 'Dry Gangrene’. 


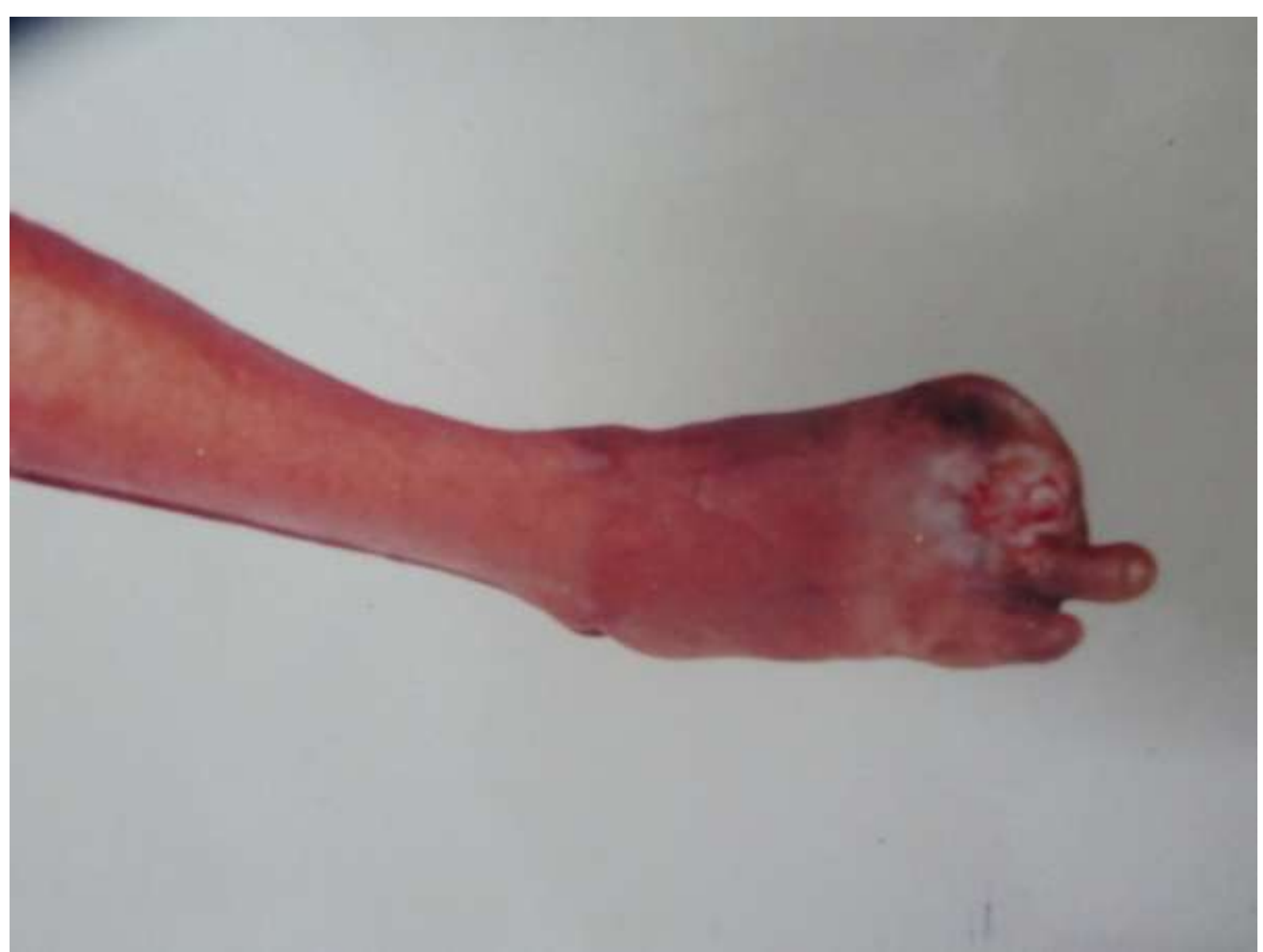

Fig 3. Showing 'Wet Gangrene’. 